\title{
Uterine Artery Embolization (UAE) for Fibroid Treatment: Results of the 6th Radiological Gynecological Expert Meeting
}

\section{Uterusarterienembolisation (UAE) zur Myombehandlung - Ergebnisse des 6. radiologisch-gynäkologischen Expertentreffens}

\author{
Authors \\ Thomas Kröncke1, *, Matthias David 2, * \\ Affiliation \\ 1 Radiologie, Klinikum Augsburg, Germany \\ 2 Gynäkologie, Charité, Berlin, Germany \\ Key words \\ uterus, embolization, leiomyoma, uterine artery embolization \\ received 23.02.2017 \\ accepted 03.04.2017 \\ Bibliography \\ DOI https://doi.org/10.1055/s-0043-108551 \\ Published online: 2017 | Fortschr Röntgenstr 2017; 189: \\ 511-514 @ Georg Thieme Verlag KG, Stuttgart · New York, \\ ISSN 1438-9029
}

Correspondence

Prof. Dr. med. Thomas Kröncke, MBA

Klinik für Diagnostische und Interventionelle Radiologie und Neuroradiologie, Klinikum Augsburg, Stenglinstr. 2,

86156 Augsburg, Germany

Tel.: ++49/8 21/4002441

Fax: ++49/821/4003312

thomas.kroencke@klinikum-augsburg.de

Prof. Dr. med. Matthias David

Charité/Universitätsmedizin Berlin

Klinik für Gynäkologie

Campus Virchow-Klinikum, Augustenburger Platz 1 ,

13353 Berlin

\section{Introduction}

Uterine artery embolization (UAE) is an organ-preserving, established, safe, and effective method in the spectrum of procedures for treating fibroid-related symptoms.

The aim of UAE is the reduction or elimination of fibroid-related symptoms, not the removal of the fibroid. At the same time the size of the fibroid is reduced.

There is consensus between the disciplines of gynecology and interventional radiology that determination of required treatment of uterine fibroids should be based on an examination and advice by a gynecologist. Comprehensive advice regarding treatment options for symptomatic uterine fibroids encompasses not only medication-based and surgical options but also UAE. The decision for or against an alternative therapy should be made taking into account the patient's desire for, and knowledge of, therapeutic alternatives, their chances of success and limitations, as well as typical side effects and possible complications (informed consent).

\footnotetext{
* For the participants of the consensus meeting.
}

In Germany, Austria and Switzerland, UAE treatment offers the possibility of a therapeutic procedure for patients with fibroidrelated symptoms which provides further individualization of therapy in cases of uterine fibroids.

\section{Aim of the consensus meeting}

The intention of the consensus meeting was to evaluate UAE. The participants in the meeting of radiological-gynecological experts, after taking into account the current literature, internationally published recommendations ${ }^{1}$ and their own experience, and after extensive discussion, came to a consensus between the two disciplines.

The panel of experts was aware that this was an assessment of the possibilities and limits of a radiological therapy held in conjunction with specialists in gynecology who do not perform the procedure themselves, but who possess expertise and experience in the diagnosis as well as treatment diseases of female reproductive organs.

1 The appendix contains references to selected relevant publications. 
The group of experts composed of 11 radiologists and 8 gynecologists met on January 14, 2017 in Berlin for the sixth radiological-gynecological consensus meeting included radiologists and gynecologists from Switzerland and Austria. After extensive and somewhat controversial -discussion, the group came to a consensus regarding the following recommendations. The consensus statement is supported by the gynecologists and radiologists listed at the end of this work.

It reflects the current state of knowledge.

\section{Structural prerequisites and quality assurance for performing UAE}

UAE should be performed only at clinics possessing the requisite gynecological and radiological expertise regarding the performing of UAE, adequate and structured pain management after the intervention, management of side effects, and the conservative and surgical treatment of fibroids.

Particularly due to the necessity for postinterventional pain management, UAE should be performed on an inpatient basis at a suitable clinic.

Prior to introducing UAE, theoretical and practical training at a center with extensive UAE experience is recommended. In addition to the legally required documentation, the calculated key radiation exposure figures (dose area product, fluoroscopy time) for UAE should be critically reviewed and optimized for quality assurance.

Participation in suitable quality assurance as defined by the professional associations is recommended.

\section{Examinations required prior to UAE}

The choice of therapy should be based on an examination performed by a gynecologist including vaginal and/or abdominal ultrasound (as a function of the size of the uterine fibroid). If ultrasound does not allow definitive diagnosis, MRI examination is indicated.

Prior to fibroid embolization, the indication for hysteroscopy and dilation and curettage must be reviewed. Findings of a cytological (Pap) smear of the uterine cervix must be unremarkable and obtained within the previous 12 months.

A negative pregnancy test as well as the following laboratory results must be available: creatinine, coagulation status, thyroid values panel (in the case of a history of thyroid disease), blood count, and CRP. Acute inflammation must be ruled out in the case history and clinically.

According to the current state of knowledge, it is not necessary to remove an implanted IUD prior to UAE.

Within the context of the informed consent discussion prior to UAE, the patient should be informed regarding the absence of preinterventional histological confirmation of the presumed uterine fibroids, as is the case with all other organ-preserving fibroid therapies.

The total risk of an undetected uterine malignancy (including uterine sarcoma) in patients undergoing surgery for a presumed fibroid is specified between $0.09 \%$ and $0.18 \%$ in the current literature. Symptoms and imaging do not allow exclusion of a uterine sarcoma in particular.

The decision for an organ-preserving medication-based, surgical, or interventional-radiological treatment option should therefore include explanation of the risks of delayed diagnosis of a sarcoma. The spreading of tumor cells after UAE has not been observed. In the case of a lack of response to treatment or a lack of a reduction in the size of the leiomyoma(s), an insufficient embolization result and the presence of a uterine sarcoma must be considered in the differential diagnosis.

\section{Indications for UAE}

A symptomatic uterine fibroid is an indication for uterine artery embolization. UAE represents an alternative to surgical and medication-based procedures and to fibroid treatment with focused ultrasound regardless of the size and number of fibroids or previous surgeries. The choice of therapy should be based on the objective of the treatment as well as the wishes of the patient.

\section{Success criteria for UAE}

UAE treatment success is primarily defined as improvement or complete elimination of the (fibroid-related) symptoms specified by the patient and to a lesser extent as a reduction in the volume of the dominant fibroid or the entire uterus after treatment.

\section{Contraindications for UAE}

\section{Technical}

Relative

- GnRH-analog pretreatment in the previous 3 months (increased risk of vasospasm of the uterine artery)

According to the current state of knowledge, the administration of ulipristal acetate does not play a role in the indication for UAE or the performing of the procedure and does not affect the results.

\section{Anatomical}

Relative

- Isolated, submucosal fibroids type 0 and I of the FIGO classification (Fédération Internationale de Gynécologie et d'Obstétrique) that are accessible for hysteroscopic resection

- Isolated pedunculated subserosal fibroids

- Supply of the fibroid(s) via an ovarian artery; the benefits and risks of additive embolization of the relevant ovarian artery should be considered.

\section{Clinical}

Absolute

- Suspected Malignancy 
- Pregnancy

- Acute genital infection

- Clinically manifest hyperthyroidism/acute thyroiditis in hyperthyroidism and planned or ongoing radioiodine therapy if iodine-containing contrast agents are used

Relative

- Documented allergic reaction to contrast agents containing iodine

- Postmenopausal patient

- Allergy to local anesthesia

- Latent hyperthyroidism

- Renal insufficiency

- Desire to become pregnant

\section{UAE in patients wishing to become pregnant}

UAE is to be considered a last resort in patients wishing to become pregnant.

\section{UAE in patients with a latent desire for children}

For patients with a symptomatic uterine fibroid and a latent desire for children, the role of UAE as a treatment option is still not sufficiently defined in the current literature.

Pregnancy after UAE is possible. The risk of miscarriage may be increased. $^{2}$

The preservation of fertility and a latent desire for children should be discussed with every patient on an interdisciplinary basis in connection with age, previous interventions, prior pregnancies, and imaging findings prior to UAE.

Before a hysterectomy is considered in a patient with extensive uterine fibroid disease who wishes to become pregnant, the possibility of performing UAE should be considered.

\section{Pregnancy after UAE}

A minimum wait time of approximately 6 months between fibroid treatment with UAE and conception is recommended.

\section{Special case: preoperative uterine artery embolization (PUAE)}

PUAE, embolization as preparation immediately before surgical myoma enucleation, can be considered and offered in individual cases for patients who absolutely want to preserve their uterus but in whom a significantly increased bleeding risk can already be assumed preoperatively and/or in whom the risk of the ultimate need for a hysterectomy is estimated to be very high "for techni-

2 Minority opinion (representatives of the DGGG and the AGR and AGE of the DGGG): In addition to miscarriage, placental abnormalities and peripartum hemorrhage may be more common after fibroid embolization (insufficient reliable data). cal reasons" (e. g. very large fibroid and/or multiple fibroids, large fibroid that is difficult to remove, fibroid with unfavorable location).

\section{Radiation protection}

Radiation protection is particularly important in UAE. Pulsed fluoroscopy should be used. Serial angiography and oblique projections should be kept to a minimum. A imaging frequency of 1 frame/second is typically sufficient. Under normal conditions, the average dose area product should be less than $50 \mathrm{~Gy} \times \mathrm{cm}^{2}$ (corresponding to $5000 \mathrm{cGy} \times \mathrm{cm}^{2}$ or $5000 \mu \mathrm{Gy} \mathrm{m} \mathrm{m}^{2}$ ) for pulsed systems. Adhering to these recommendations radiation exposure is in the range of 2 to 3 CT examinations of the abdomen.

\section{Side effects}

The following are described as relevant side effects and complications of UAE: Post-embolization syndrome, amenorrhea as a consequence of impairment or failure of ovarian function, pain, discharge, angiography-related complications (e. g. groin hematoma), vaginal discharge of fibroid material, hot flashes, endometritis/myometritis, deep vein thrombosis/pulmonary embolus.

Uterine discharge can be normal in the first weeks after UAE. In the case of abnormal vaginal discharge, the patient should be diagnosed and treated for infection. Menorrhagia, cramping of the lower abdomen, discharge (sloughing) of tissue can occur in the case of submucosal fibroids in particular. Depending on the symptoms and the findings of diagnostic imaging, hysteroscopicfibroid resection or transvaginal removal of a fibroid may be indicated likewise to the treatment indicated in cases of spontaneous fibroid passage or expulsion. Hysterectomy is not indicated a priori. In cases of doubt, the center conducting the UAE procedure should be contacted.

\section{Post-treatment examination after UAE}

Post-treatment examination by a specialist is recommended approx. 6 months after UAE.

Imaging procedures are useful (e.g., sonography in conjunction with Doppler sonography, MRI). Further clarification is required if the therapy is unsuccessful (no improvement of symptoms and/or size progression of the fibroid), or there are unusual imaging findings such as an increase in the size of the fibroid(s) or uterus and/or a lack of devascularization of the fibroid(s).

\section{Outlook}

These recommendations regarding uterine artery embolization in the case of fibroid-related symptoms are to be revised again in 2019 based on the available data and experience.

\section{Appendix}

\section{Consensus meeting participants}

PD Dr. med. Ralf Adamus/ Nuremberg

Dr. med. Robert Armbrust/ Berlin 
Dr. med. Michael Bartsch/ Hamburg

Prof. Dr. med. Michael Bohlmann/ Mannheim

Dr. med. Alexander Burges/ Munich

Prof. Dr. med. Matthias David/ Berlin

Prof. Dr. med. Markus Düx/ Frankfurt a.M.

Prof. Dr. med. Dr. phil. Dr. h. c. mult. Andreas D. Ebert/ Berlin

Prof. Dr. med. Peyman Hadji/ Frankfurt a.M.

Dr. med. Thomas Hess/ Winterthur $(\mathrm{CH})$

Prof. Dr. med. Thomas Kröncke/ Augsburg

Prof. Dr. med. Peter Landwehr/ Hannover

Dr. med. Matthias Matzko/ Dachau

Prof. Dr. med. Thomas Pfammatter/ Zürich (CH)

Dr. med. Gernot Rott/ Duisburg

PD Dr. med. Dirk Schnapauff/ Berlin

Prof. Dr. med. Uwe Ulrich/ Berlin

Prof. Dr. med. Dierk Vorwerk/ Ingolstadt

PD Dr. Peter Waldenberger/ Salzburg (AT)

\section{Participating professional associations and working groups}

AGE, Arbeitsgemeinschaft Gynäkologische Endoskopie der DGGG [Gynecological Endoscopy Working Group of the German Society of Gynecology and Obstetrics]

AGR, Arbeitsgemeinschaft gynäkologischer Radiologie der DGGG [Gynecological Radiology Working Group of the German Society of Gynecology and Obstetrics]

AG URZ, Arbeitsgemeinschaft Universitärer Reproduktionsmedizinischer Zentren der DGGG [Working Group of University Reproductive Medicine Centers of the German Society of Gynecology and Obstetrics]

BVF, Berufsverband der Frauenärzte [Professional Association of Gynecologists]

DeGIR, Deutsche Gesellschaft für Interventionelle Radiologie und minimal-invasive Therapie [German Society for Interventional Radiology and Minimally Invasive Therapy]

DGGEF, Arbeitsgemeinschaft Gynäkologische Endokrinologie und Fortpflanzungsmedizin e. V. [Working Group for Gynecological Endocrinology and Reproductive Medicine]

DGGG, Deutsche Gesellschaft für Gynäkologie und Geburtshilfe [German Society of Gynecology and Obstetrics]

DRG, Deutsche Röntgengesellschaft

NOGGO, Nordostdeutsche Gesellschaft für Gynäkologische Onkologie [Northeastern German Society of Gynecological Oncology] ÖGIR, Österreichische Gesellschaft für Interventionelle Radiologie [Austrian Society of Interventional Radiology]

SGGG, Schweizerische Gesellschaft für Gynäkologie und Geburtshilfe [Swiss Society of Gynecology and Obstetrics]

SSVIR, Swiss Society of Cardiovascular and Interventional Radiology

\section{References to relevant publications}

1. Beckmann MW, Juhasz-Böss I, Denschlag D et al. Surgical methods for the treatment of uterine fibroids - risk of uterine sarcoma and problems of morcellation: position paper of the DGGG. Geburtsh Frauenheilk 2015; 75: 148 - 164

2. de Bruijn AM, Ankum WM, Reekers JA, et al. Uterine artery embolization vs hysterectomy in the treatment of symptomatic uterine fibroids: 10-year outcomes from the randomized EMMY trial. Am J Obstet Gynecol 2016;215:745.e1-e12

3. Denschlag D., F. C. Thiel, S. Ackermann, P. Harter, I. JuhaszBoess, P. Mallmann, H.-G. Strauss, U. Ulrich, L.-C. Horn, D. Schmidt, D. Vordermark, T. Vogl, P. Reichardt, P. Gaß, M. Gebhardt, M. W. Beckmann. Uterine Sarkome. Leitlinie der DGGG (S2k-Level, AWMF-Registernummer 015/074, August 2015) Geburtsh Frauenheilk 2015; 75; e3 DOI: 10.1055/s-0035 1558288

4. Gupta JK, Sinha A, Lumsden MA, Hickey M. Uterine artery embolization for symptomatic uterine fibroids. Cochrane Database of Systematic Reviews 2014, Issue 12. Art. No.: CD005 073. DOI: 10.1002/14651 858.CD005 073.pub4.

5. Kainsbak J, Hansen ES, Dueholm M. Literature review of outcomes and prevalence and case report of leiomyosarcomas and non-typical uterine smooth muscle leiomyoma tumors treated with uterine artery embolization. Eur J Obstet Gynecol Reprod Biol. 2015 Aug;191:130 - 137. doi: 10.1016/j. ejogrb.2015.05.018. Epub 2015 Jun 11.

6. Rodriguez AM et al. Incidence of occult leiomyosarcoma in presumed morcellation cases: a database study. European Journal of Obstetrics \& Gynecology and Reproductive Biology 197 (2016) $31-35$

7. van der Kooij SM, Bipat S, Hehenkamp WJK, et al. Uterine artery embolization versus surgery in the treatment of symptomatic fibroids: a systematic review and metaanalysis. Am J Obstet Gynecol 2011;205:317.e1-317.e18

8. Vercellini $P$ et al. Prevalence of unexpected leiomyosarcoma at myomectomy: a descriptive study (research letter). Am J Obstet Gynecol 2016, 292 - 294 http://dx.doi.org/10.1016/j. ajog.2015.09.092

9. Wright JD, Tergas Al, Cui R, et al. Use of electric power morcellation and prevalence of underlying cancer in women who undergo myomectomy. JAMA Oncol 2015; 1: 69 - 77

Conflict of Interest

The authors declare that they have no conflict of interest.

Published simultaneously

Published simultaneously in Geburtshilfe und Frauenheilkunde 6-2017: Geburtshilfe Frauenheilkd 2017; DOI:10.1055/s-0043-106259 